Research Journal of Applied Sciences 7 (7): 340-343, 2012

ISSN: $1815-932 \mathrm{X}$

(C) Medwell Journals, 2012

\title{
Effects of a Multisensory Programme on Dyslexic Students: Identification and Mastery of the Alphabet
}

\author{
Rohaty Mohd. Majzub, Mohd. Anuar Abdullah and Zahara Aziz \\ Faculty of Education, National University of Malaysia, 43600 Bangi, Selangor, Malaysia
}

\begin{abstract}
Reading skill is an important process in learning and knowledge acquisition. However, dyslexic students face problems in reading. The main objective of this study was to compare the effectiveness of the multisensory method in teaching dyslexic students compared to the traditional method. The specific objectives were to investigate whether there were significant differences on dyslexic students alphabet recognition problem and alphabet mastering skill after the implementation of the multisensory program. The sample of study consisted of 8 and 9 years old elementary school children who were attending remedial education classes from twelve schools at the District of Hilir Perak, Malaysia. The equivalence of the samples was determined based upon the Dyslexia identification test which formed the experimental group and control group. The mean pre-test of the experimental group for alphabet identification was $45.29, \mathrm{SD}=7.59$ whereas the post-test was $50.97, \mathrm{SD}=7.59$. The mean pre-test of alphabet identification for the control group was 45.29 , standard deviation 7.59 and the post-test score was $77.74, \mathrm{SD}=5.03$; whereas for the control group was the pre-test was 45.29 , standard deviation 7.59 and the post-test was 50.97, standard deviation 6.59. The t-test results showed significant differences. The mean post-test score of the experimental group for alphabet mastery was 31.19 , $\mathrm{SD}=2.31$ compared to the control group $(20.10, \mathrm{SD}=2.26)$. In conclusion the t-test (alpha 0.05) showed there were significant differences for alphabet identification and alphabet mastery through using the multisensory method. Teacher training programs can integrate the multisensory method to enhance the learning of dyslexic students.
\end{abstract}

Key words: Multisensory program, dyslexic students, alphabet identification, alphabet mastering skills, Malaysia

\section{INTRODUCTION}

In a knowledge based and an exam oriented society like Malaysia intellectual achievement is emphasised to serve the needs of the community and country. Mastering basic skills like reading, writing and arithmetic is of paramount importance. This has cause concerned and ambitious parents to ensure that their children excel in those aspects. Most children found that reading skill is a simple process that can be taught at the initial stage of preschool and by mastering this skill, knowledge can be procured (Adams, 1990; Moats, 2000; Snow et al.,1998; Snowling et al., 2000).

Baba (2004) stated that the most effective way to gain knowledge is hard work in reading. Reading is a skill which must be mastered by everyone who wants to succeed. However, dyslexic children face problems in reading.

The Special Education Department, Ministry of Education, Malaysia has defined dyslexic children as children who have difficulties in spelling, reading and writing skills. According to Mahat (2004) the Ministry of Education, Malaysia was concerned about the education of special needs children namely dyslexic children. The Louisiana Law for the Education of Dyslexic Students explains that dyslexia is caused by disorders in oral and written language despite having a good level of intelligence. Disorders and difficulties may occur in alphabet, reading, comprehension, writing and spelling. Students with dyslexic symptoms have difficulties problems in basic literacy and numeracy skills (Miles and Hales, 1994).

Dyslexia is best described as a combination of abilities and difficulties which affect the learning process in one or more of reading, spelling and writing. Accompanying weakness may be identified in areas of speed of processing, short term memory, sequencing, auditory and/or visual perception, spoken language and motor skills. It is particularly related to mastering and using written language which may include alphabetic, numeric and musical notation. Dyslexia can often result in the feeling of disorientation. This can have major effects

Corresponding Author: Rohaty Mohd Majzub, Faculty of Education, Universiti Kebangsaan Malaysia, Selangor, Malaysia 
such as not knowing the difference between left and right not being able to organize time and/or the inability to follow a set of instructions sequentially. These effects reach well beyond the classroom and will encroach on every aspects of life. An accumulation of such difficulties and their effects can adversely affect a person's selfimage. Students with dyslexia can often feel dumb and misunderstood. If she has experienced problems at school they may be less motivated to continue in the mainstream of the educational system (Miles and Hales, 1994).

Problem statement: Reading is important in transforming and constructing knowledge from the reading materials. The skill and the ability to read is a complex process depending on two major components, namely the identification of words and language understanding or comprehension (Catts et al., 2008; Gardner, 1983; Vellutino et al., 2004).

The word identification component serves to translate the text into linguistic information. The component on functional language understanding interprets the linguistic information to get the meaning conveyed by the text. Although, the final goal focuses the comprehension of language it is not likely to happen if one does not know the words printed in the text. This indicates if one has a problem in the word identification language understanding will also be affected.

Richards et al. (1999) stated that researchers from The University of Washington have indicated children with dyslexia usually use five times the capacity of brain compared with normal children. Their study also found that chemical in the brain of dyslexic children is different from normal children.

Their research also shows that society does not realize to what extent dyslexic children face the difficulties in reading, writing and arithmetic. Parents should however not blame the teachers or schools that fail to teach their children with dyslexic symptoms, unless the teachers were given specific trainng on dyslexia. Berninger and his study team concluded that effects of dyslexia can be alleviated through educational intervention. Anderson and Meier-Hedde (2001) state that past studies show the link between nerve function and brain disorders.

Based on the problem statement shown, it can be concluded that this research is important because teachers generally lack knowledge and skills in handling children with dyslexia. Subsequently, dsylexic students do not receive the attention from teachers and fail in the examinations compared to their peers. Teachers should enhance the learning of dyslexic students through a more strategic method in teaching. The introduction of mulitsensory method in teaching dyslexic students is one of the popular methods used by educators.
Aim of study: The aim of the study was to evaluate the effects of the multisensory method on the teaching and learning of dyslexic students.

Objectives: To investigate whether there were significant differences on dyslexic students alphabet identification problem after the implementation of the multisensory method as compared to the traditional method; to investigate whether there were significant differences on dyslexic students alphabet mastering skill after the implementation of the multisensory approach as compared to the traditional method.

Review of the literature: There are several theories and strategies related to multisensory teaching method. Among the pioneers is Samuel Orton. He has introduced the teaching method emphasizing multisensory visual, auditory and kinaesthetic-tactile skills. The memory of dyslexic students in teaching and learning will be enhanced though the multisensory method. The strength of the multisensory method is that it integrates visual, auditory and kinesthetic elements. The multisensory method supports the multiple intelligences forwarded by Gardner (1983).

Orton (1925) who conducted research on dyslexia stated that the difficulty in reading occured when the visual images sent to the right brain were disturbed by imputs from the left brain recent studies in same field were conducted by researchers from Georgetown University Medical Center. This study explored children who have difficulties in reading. The findings confirm theories or hypothese made by Orton. This study showed that differences in phonological skills were associated with differences in the brain in the process of reading. Disorder in the nerves will cause shortage in phonological skills amongst dyslexic children.

According to Eric teaching through visual, auditory, kinesthetic and tactile activities represents a combination of spectral diversity in the learning process. For example visual activities adapt information or new knowledge through selected teaching aids such as diagrams, colouring, drawing, graphs, numbers, order graphics, puzzles and crossword puzzels, auditory teaching approach focuses on learning letter sounds. Children will be exposed to hear pronunciation of the word through the use of multimedia

\section{MATERIALS AND METHODS}

This is a Quasi experiment that focuses on the application of a multisensory method of teaching, reading and writing to dyslexic students. This study examines differences in reading and writing skills of two groups of 
students. The experimental group was taught by the multisensory method while the the control group was taught by the traditional method of teaching. The Quasi experimental design was used to assess the effectiveness of both methods of teaching. Samples in this study were students who have studied in remedial education classes from twelve schools in the district of Hilir Perak. Samples were obtained through screening and diagnostic evaluation. In addition, the sample was nominated by the mainstream class teacher. These students were studying in year two and three of the elementary school and were in the age range 8-9 years old. Samples were tested for dyslexia detection by using Dyslexia checklist (ISD) developed by the Ministry of Education, Malaysia. To ensure that the samples selected in experiment have dyslexic symptoms in using Malay, the samples were screened again using the Dyslexic Malay Language Reading test. Through these tests a total of 62 students from 12 schools were obtained. Thirty one students were placed in the control group and another 31 students were placed in the experimenal group. Jordan Oral Screening Test (JOST) was administrated after the multisensory and traditional methods were conducted for 3 months. The JOST involves two components namely identification mastery of the alphabet. The former involves the ability to write alphabets and syallables while the latter involves writing alphabets and numbers sequencing alphabets and matching alphabets with the coresponding pictures given.

\section{RESULTS}

Table 1 shows the mean, Standard Deviation (SD) of the pre-test and post-test mean score and the increase in the overall performance of both the experimental group (multisensory method) and control group (traditional method). The mean pre-test of the experimental group was $92.7, \mathrm{SD} 6.53$ and the mean pre-test of the control group was $91.6, \mathrm{SD} 7.03$. The finding shows the performance of the two groups is similar before the treatment. The mean post-test scores of the experimental group was 211.7, SD 10.28 compared to the post-test mean of the control group (119.8, SD 8.08). The findings of the pre-test and post-test both showed significant differences between two groups after the treatment. The findings show an increase in the experimental group is higher than the increase for the control group.

Table 2 shows the mean, Standard Deviation (SD) of the pre-test and post-test scores on alphabet identification for the experimental group and the control group. The mean pre-test for the experimental group was 45.29 , SD 7.59 and for the control group was 45.29 ,
Table 1: Means and SD pre-test, post-test: experimental control group Experimental group $(n=31) \quad$ Control group $(n=31)$

\begin{tabular}{lccccrc} 
Statical & $\begin{array}{c}\text { Pre- } \\
\text { analy sis }\end{array}$ & $\begin{array}{c}\text { Post- } \\
\text { test }\end{array}$ & $\begin{array}{c}\text { Mean score } \\
\text { increase }\end{array}$ & $\begin{array}{c}\text { Pre- } \\
\text { test }\end{array}$ & $\begin{array}{c}\text { Post- } \\
\text { Mean }\end{array}$ & $\begin{array}{c}\text { Mean score } \\
\text { test }\end{array}$ \\
\hline Mean & 92.7 & 211.7 & 119 & 91.6 & 119.80 & 28.2 \\
SD & 6.53 & 10.28 & - & 7.03 & 8.08 & - \\
\hline
\end{tabular}

Table 2: Mean and standard deviation of pre and post-test of experimental and control group: alphabet identification Experimental group $(n=31) \quad$ Control group $(n=31)$

\begin{tabular}{lcccccc}
$\begin{array}{l}\text { Statical } \\
\text { analysis }\end{array}$ & $\begin{array}{c}\text { Pre- } \\
\text { test }\end{array}$ & $\begin{array}{c}\text { Post- } \\
\text { test }\end{array}$ & $\begin{array}{c}\text { Mean score } \\
\text { increase }\end{array}$ & $\begin{array}{c}\text { Pre- } \\
\text { test }\end{array}$ & $\begin{array}{c}\text { Post- } \\
\text { test }\end{array}$ & $\begin{array}{c}\text { Mean score } \\
\text { increase }\end{array}$ \\
\hline Mean & 45.29 & 77.74 & 32.45 & 45.29 & 50.97 & 5.68 \\
SD & 7.59 & 5.03 & - & 7.59 & 6.59 & - \\
\hline
\end{tabular}

Table 3: Post-test means and standard deviation of the experimental group and control group: mastery of the alphabet

\begin{tabular}{|c|c|c|c|c|c|c|}
\hline \multirow[b]{2}{*}{$\begin{array}{l}\text { Statical } \\
\text { analysis } \\
\end{array}$} & \multicolumn{3}{|c|}{ Experimental group $(n=31)$} & \multicolumn{3}{|c|}{ Control group $(n=31)$} \\
\hline & $\begin{array}{l}\text { Pre- } \\
\text { test }\end{array}$ & $\begin{array}{c}\text { Post- } \\
\text { test }\end{array}$ & $\begin{array}{c}\text { Mean score } \\
\text { increase }\end{array}$ & $\begin{array}{l}\text { Pre- } \\
\text { test }\end{array}$ & $\begin{array}{c}\text { Post- } \\
\text { test }\end{array}$ & $\begin{array}{c}\text { Mean score } \\
\text { increase }\end{array}$ \\
\hline ea & 16.23 & 31.19 & 14 & 16. & 20.10 & 4.07 \\
\hline & 2.64 & 2.31 & - & 2.49 & 2.25 & - \\
\hline
\end{tabular}

$\mathrm{SD} 7.59)$. The findings indicated the similarity between the two groups before treatment. The post-test mean scores for the experimental group was 77.4, SD 5.03; the post-test mean for the control group was 50.97 , SD 6.59. The pre-test and post-test scores indicated significant differences between two groups existed after the treatment. Both groups showed an increase in the mean score after the treatment with the experimental group 77.7 and the control group 50.97. However, the finding showed that the increase in experimental group (mean $=32.45$ ) was higher than the increase in the control group (mean = 5.68). The t-test $(\mathrm{p}=0.05)$ showed significant difference between the two group.

Table 3 shows the mean and Standard Deviation (SD) pre-test and post-test mean scores in alphabet mastery of the experimental and control group. The pre-test mean for the experimental groups was $16.23, \mathrm{SD} 2.64$ and for the control group 16.03, SD 2.49 indicating similarities between two groups before treatment. The post-test mean for the experimental group was $31.19, \mathrm{SD} 2.31$ and for the control group was 20.10, SD 2.25. Both groups showed an increase in the mean score after the treatment however the increase in the experimental group (mean $=14.96$ ) was higher than the increase in the control group. The t-test $(\mathrm{p}=0.05)$ showed significant difference between the mean score of the two group.

\section{DISCUSSION}

Alphabet identification. The findings show that the mean score in alphabet identification of the experimental group 
after the implementation of the multisensory treatment was higher $($ mean $=32.45)$ compared with control group $($ mean $=5.68)$.

These findings show similarities with the findings of Hook et al. (2001) who used the multisensory method known as Fast For Word. A total of 31 children with dyslexia participated in this study. Pre and post-tests were conducted to see the students abilities in letter, word recognition and word formation. Post-test results showed a significant increase in the ability to identify letters and words.

Mastery of the alphabet: Significant meanincrease for the experimental group using the multisensory method was recorded compared to the control group. The mean pre-test score for the experimental group was (16.23) and control group's mean was (16.03). The experimental group who were given the multisensory treatment obtained (mean $=31.96)$ and the control group who received the traditional method obtained $($ mean $=20.10)$. These results indicated an increase in the mean scores using the multisensory method as compared to the traditional method.

These findings parallel the findings of Oakland et al. (1998) who conducted research on the effectiveness of the multisensory method. Children who were taught by teachers who were trained in the multisensory method showed significant gain scores in comprehension, reading, sounding syllables and letters.

\section{CONCLUSION}

The findings of the study showed the effectiveness of the multisensory method in teaching dyslexic students compared to the traditional method on students identification and mastery of the alphabet. The use of the multisensory method thus can be said to enhance students performance in reading and writing.

\section{IMPLICATIONS}

The findings have an impact on educational policies and practices. Firstly teacher education programs can provide trainning for teachers to employ the multisensory method to help enhance the learning of dyslexic students. Secondly curriculum modules can be developed to focus on the multisensory elements in the curriculum for dyslexic students. Parents can be trained as educators to help their dyslexic children at home. Future research can be extended to studying the effects of using multisensory method of teaching on dyslexic childrens' motivation, self concept and locus of control. Further research can also be conducted to examine the effects of the multisensory method in different subjects including mathematics and sciences.

\section{REFERENCES}

Adams, M.J., 1990. Beginning to Read: Thinking and Learning about Print. MIT Press, Cambridge, MA., USA., ISBN-13: 9780262510769 , Pages: 494.

Anderson, P.L. and R. Meier-Hedde, 2001. Early case reports of dyslexia in the United States and Europe. J. Learn. Disabilities, 34: 9-21.

Baba, Z., 2004. Speech on new year 2004. Director National Library of Malaysia, Malaysia.

Catts. H.W., M.S. Bridges and T.D. Little, 2008. Reading achievement growth in children with language impairments. J. Speech Lang. Hearing Res., 51: 1569-1579.

Gardner, H., 1983. Frames of Mind: The Theory of Multiple Intelligences. 2nd Edn., Basic Books, New York, USA., ISBN-13: 9780465025084, Pages: 440.

Hook, P.E., P. Macaruso and S. Jones, 2001. Efficacy of fast for word training on facilitating acquisition of reading skills by children with reading difficulties: A longitudinal study. Ann. Dyslexia, 51: 73-96.

Mahat, A.R., 2004. Learning round table 2004. Institute of International Language, Kuala Lumpur, Malaysia.

Miles, T.R. and G. Hales, 1994. Dyslexia Matters. Whur Publishers, London, UK., ISBN-13: 9781897635117, Pages: 226.

Moats, L.C., 2000. Speech to Print: Language Essentials for Teachers. Paul H. Brookes Publ., Baltimore, MD., USA., ISBN-13: 9781557663870 , Pages: 243.

Oakland, T., J.L. Black, G. Stanford, N.L. Nussbaum and R.R. Balise, 1998. An evaluation of the dyslexia training program: A multisensory method for promoting reading in students with reading disabilities. J. Learn. Disabilities, 31: 140-147.

Orton, S.T., 1925. Word-blindness in school children. Arch. Neurol. Psychiatry, 14: 581-615.

Richards, T.L., S.R. Dager, D. Corina, S. Serafini and A.C. Heide et al., 1999. Dyslexic children have abnormal brain lactate response to reading-related language tasks. Am. J. Neurodiol., 20: 1393-1398.

Snow, C.E., M.S. Burns and P. Griffin, 1998. Preventing Reading Difficulties in Young Children. National Academy Press, Washington, DC., USA., ISBN-13: 9780309064187, Pages: 432.

Snowling, M., D.V.M. Bishop and S.E. Stothard, 2000. Is preschool language impairment a risk factor for dyslexia in adolescence? J. Child Psychol. Psychiatry, 41: 587-601

Vellutino, F.R., J.M. Fletcher, M.J. Snowling and D.M. Scanlon, 2004. Specific reading disability (dyslexia): What have we learned in the past four decades? J. Child Psychol. Psychiatry, 45: 2-40. 